SEDIMENT TRANSPORT PHENOMENA IN THE ZAIRE RIVER.

\title{
J.J. PETERS
}

Laboratoire de Recherches Hydrauliques, Borgerhout (Belgium).

SUMMARY

Sediment transport measurements have been made in the estuary of the Zaire river since 1968. The results show that bed and channel morphology is a predominant factor of the sediment distribution and transport. Vertical distribution of sediment transport near the bed reveals high rates in a layer of a thickness of a few decimeters, moving close to the bed, and a very erratic transport on the bed. At constant velocity, the influence of varying bottom shear stresses is shown in time series of bed load and suspended load. These observations could be related to the burst-sweep cycle. The successful application of Bagnold's approach for computation of sediment transport at single stations tends to prove the validity of power-related theories for large alluvial streams.

INTRODUCTION

Most of the experimental laws governing sediment transport are based on the results of flume tests. There is a lack of reliable data of field measurements especially for large rivers, partly due to the imperfection and inefficiency of devices and instruments used in sediment transport observations, partly to the complexity and diversity of the transport phenomena, and finally partly to the almost non stationnary conditions of natural flows.

In the upstream reach of the Zaire estuary, the flow regime may be considered as stationnary with very high discharges and because of the small tidal effect. Channels are wide and deep, and provide an exceptionnal site for investigations on sediment transport.

The Zaire (or Congo) river is the second largest river of the world regarding the annual fresh water inflow to the oceans. River discharges range from $23000 \mathrm{~m}^{3} / \mathrm{s}$ to $80000 \mathrm{~m}^{3} / \mathrm{s}$ and floods evolve very slowly. The partition of the watershed at each side of the equator explains the very 
small ratio between the extreme river discharges. The mean sediment concentration is one of the lowest of the large rivers.

Since 1967, a research project of the Belgian State Hydraulic Laboratory involves the study of the improvement of the navigation in the braided and meandering area near the mouth of the Zaïre estuary. Physica1 model studies and field investigations provided informations about the sediment transport mechanisms and allowed prediction of the future evolutions of the meanders. In this way, dredging operations could be reduced, becoming more efficient.

The area under investigation is located in the estuarine reach which is $150 \mathrm{~km}$ long (Fig.1 and Fig.2). The main part of the watershed of the Zairre constitutes what is called the "central basin" (cuvette centrale) separated from the Atlantic Ocean by the "Cristal Mountains". The mean river slopes are generally very small, and only fine sands reach Kinshasa and pass through the rapids and waterfalls of the cristal Mountains to Matadi at the head of the estuary. This configuration regulates the river sediment input of the estuary. The braided area, $60 \mathrm{~km} \mathrm{long,} \mathrm{begins}$ at the harbour of Boma, $60 \mathrm{~km}$ downstream the harbour of Matadi, and ends at the head of a large submarine cañon.

\section{CHARACTERISTICS OF THE BRAIDED AREA}

F1ow.

During average floods, discharges vary from $30000 \mathrm{~m}^{3} / \mathrm{s}$ in August to $60000 \mathrm{~m}^{3} / \mathrm{s}$ in December (Fig.3). The tidal amplitude at the mouth amounts to $1 \mathrm{~m}$, decreasing rapidly upstreams under the influence of the freshwater flow. River sediments fill up progressively the very deep submarine cañon in which the salt wedge is located.

The mean surface slope drops from $10^{-4}$ near Bona to less than $10^{-5}$ near Malela at the downstream limit of the braided area. Mean velocities range from 1 to $2 \mathrm{~m} / \mathrm{s}$ but surface velocities locally reach $3 \mathrm{~m} / \mathrm{s}$ and more at high discharges, even in the deepest regions $(30 \mathrm{~m})$. Near Boma, tidal variations are small and flow conditions may be considered as almost stationnary. Near Malela, tidal variations of velocities are high, often of the same order of magnitude as the mean velocity. Shear velocities vary from 0.01 to $0.15 \mathrm{~m} / \mathrm{s}$, but are generally less than $0.10 \mathrm{~m} / \mathrm{s}$. The large bedforms, and the intricated channel morphology cause very im- 


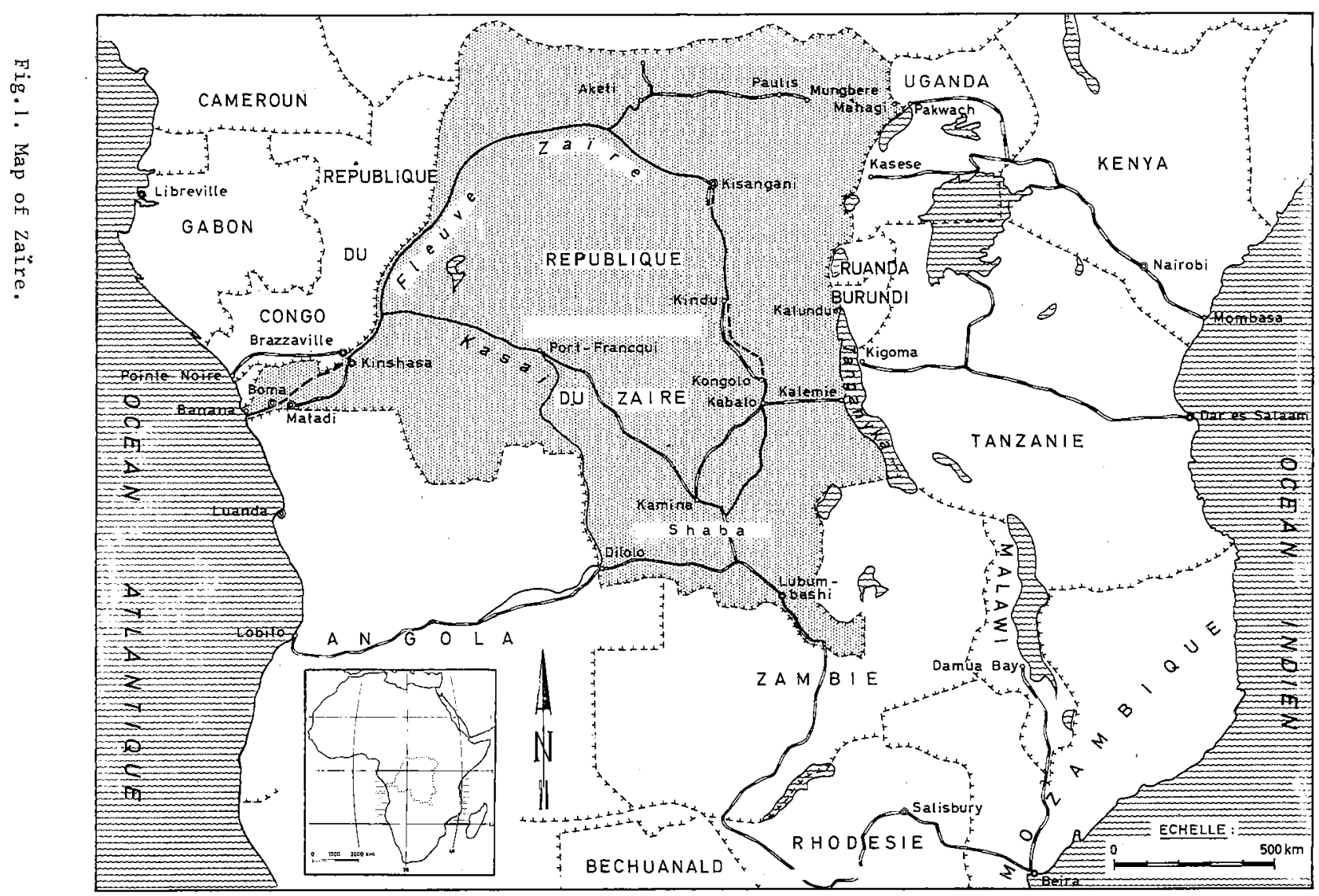


SALT WEDGE ESTUARY

BRAIDED AREA

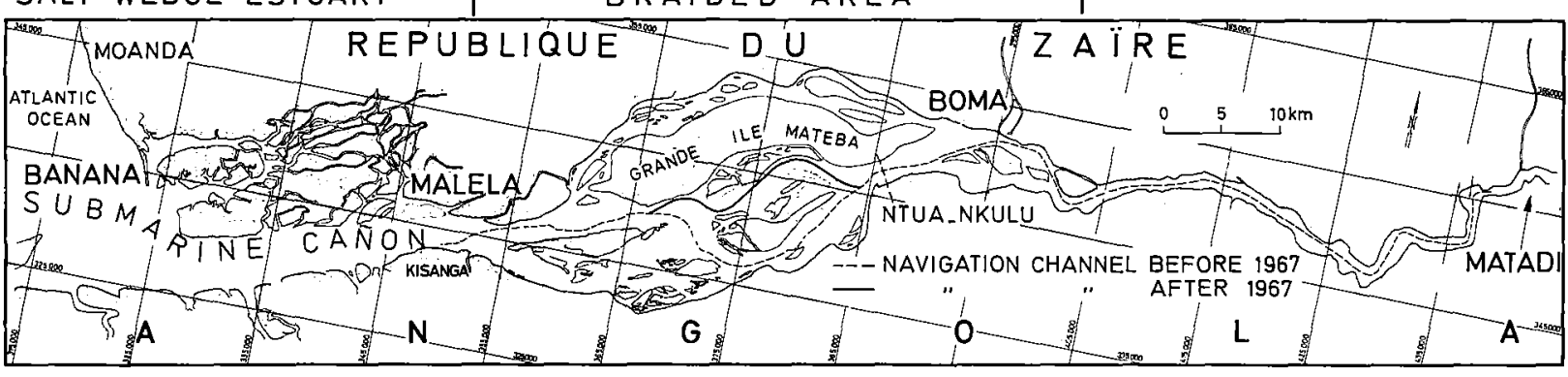

Fig.2. The Zaire estuary.

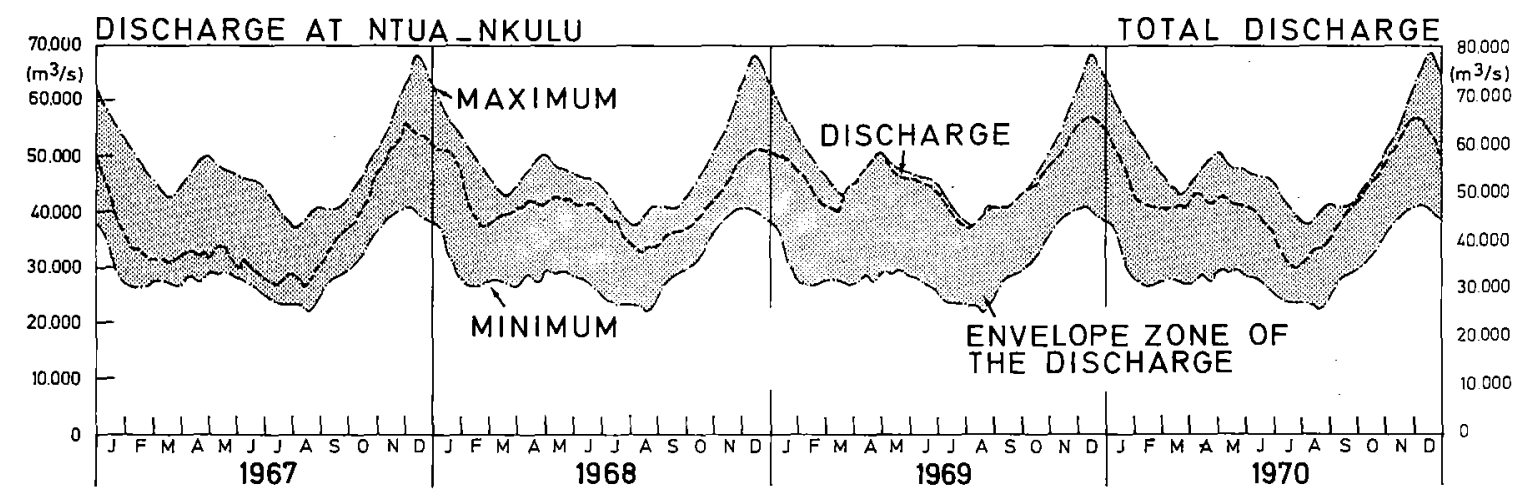

Fig.3. Fresh water inflow of the Zaire estuary. 
portant secondary currents and a strong turbulent flow.

\section{Sediments.}

Sediments entering the braided area contain pebbles, gravels, sands, and silts. The inflow rate of the sand fraction at Boma vary between $10000 \mathrm{~m}^{3} /$ day to $500000 \mathrm{~m}^{3} /$ day and amounts to $50000 \mathrm{~m}^{3} /$ day at mean river discharge. Selective sedimentation occurs along the braided area and sediment sizes drop regularly from $1 \mathrm{~mm}$ to $0.3 \mathrm{~mm}$ over a distance of $40 \mathrm{~km}$ (Fig.4). Only the smallest particles reach the Ocean. Large differences of sediment sizes in and between cross-sections are due to the influence of secondary currents.

Bed and channel morphology.

Bedforms are generally large scale dunes; their wavelength and -amplitudes average respectively $100 \mathrm{~m}$ and $2 \mathrm{~m}$. They move at a velocity ranging from $2 \mathrm{~m}$ to $10 \mathrm{~m}$ a day. At high river discharges and for sediment sizes smaller than $0.5 \mathrm{~mm}$, these dunes are flattened and other bedforms appear similar to small scale dunes. Their wavelengths and -amplitudes average then respectively $20 \mathrm{~m}$ and $1 \mathrm{~m}$. The characteristics and the behaviour of these bedforms are poorly known, however corresponding sediment transport is always high. These bedforms exist on shoals as well as in deeper channels. During a high flood in 1968, these small scale bedforms were developping in the Northern channel, where the sediment size was smaller than $0.5 \mathrm{~mm}$, while the large scale bedforms remain in the Southern channel where the sediment size was larger than $0.5 \mathrm{~mm}$ (Fig.5). By plotting the mean power of the flow per unit area versus sediment size, it can be seen that the small scale bedforms develop in the Southern channel at conditions of upper flow regime (Fig.6). The Froude number of the flow average 0.1 , and the accepted classification of bedforms would suggest a plane bed.

Meanders move sometimes very quickly : concave banks in bends may erode at a rate of $100 \mathrm{~m}$ per year, or even more. Many rocks and rocky bars influence strongly the meandering of the different channels of the braided area, and therefore analysis of the meander characteristics are not very meaningful. Length, meander belt width, meander radius and channel width, average respectively $12 \mathrm{~km}, 3 \mathrm{~km}, 3 \mathrm{~km}$, and $1.5 \mathrm{~km}$. The interconnections between the different branches of the braided area, where sediments have different sizes and move at different speeds, complicate 


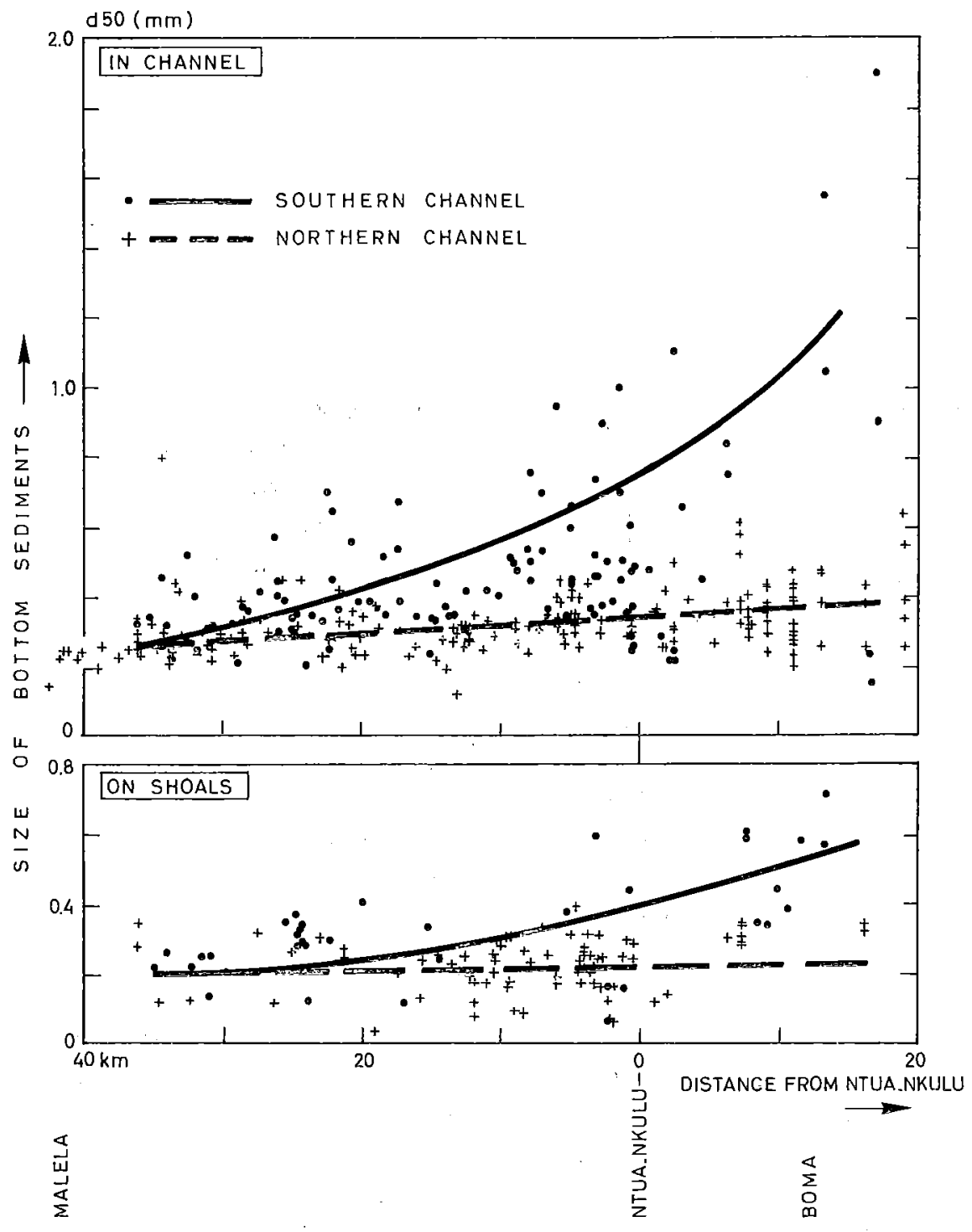

Fig.4. Selective sedimentation in the braided axea. 


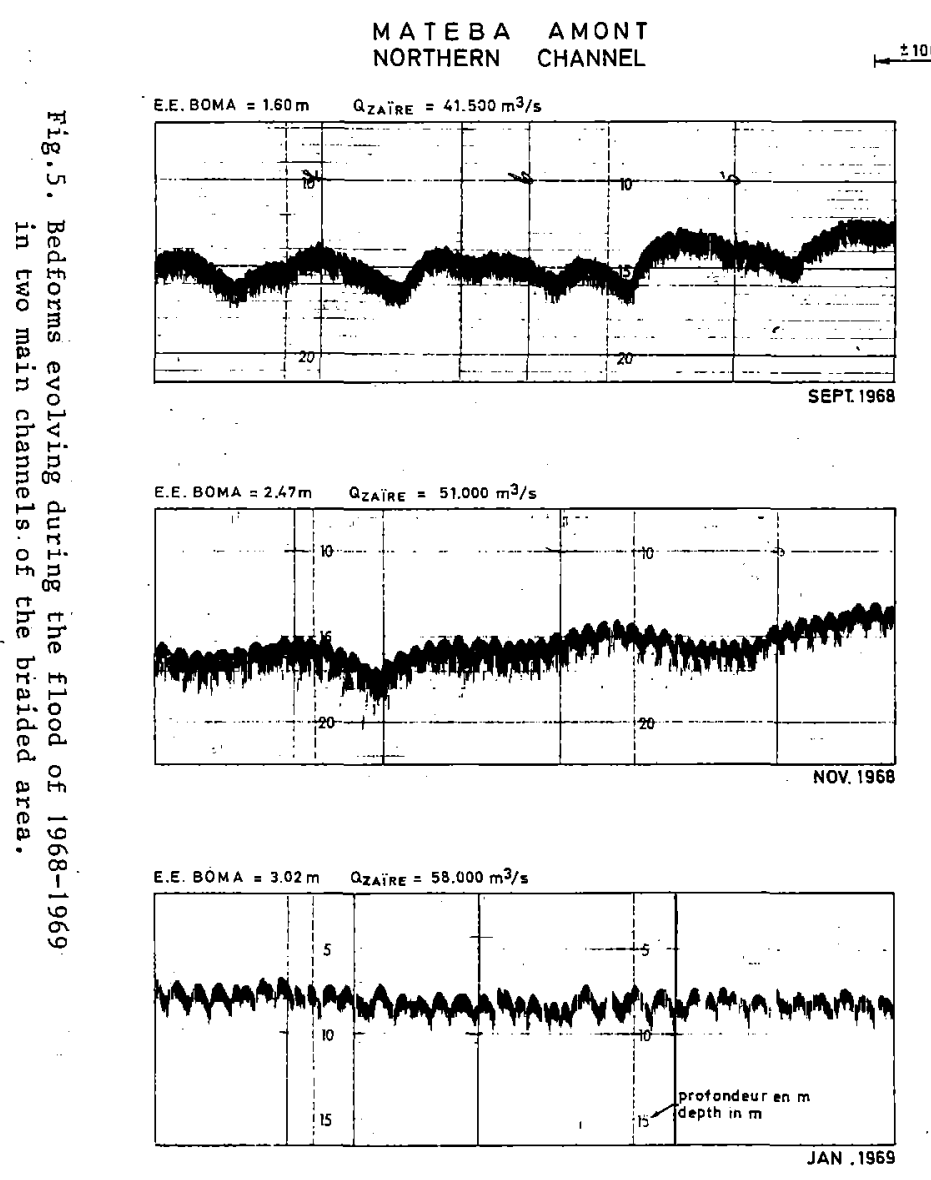




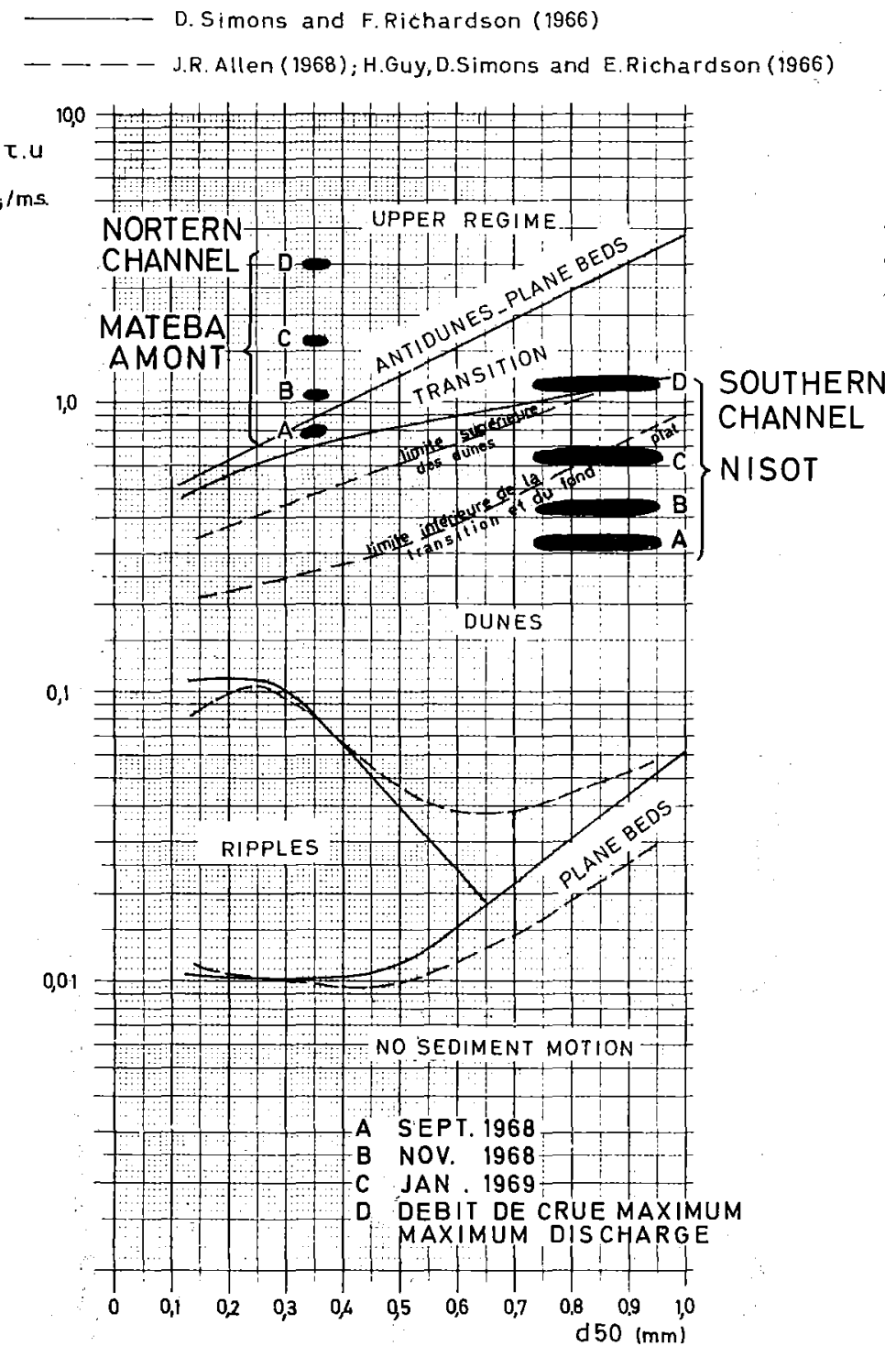

₹u: Puissance du fleuve par unité de surface du lit - Stream power

d: Diametre moyen du sédiment - Median fall diameter

Fig.6. Classification of bedforms observed during the flood of 1968-1969 in two main channels of the braided area (see fig.5). 
the analysis and the prediction of the evolution of the meanders.

SEDIMENT TRANSPORT MEASUREMENTS

Instrumentation and techniques.

As the goal of the investigations was the improvement of the navigation with dredging and eventually hydraulic structures, measurements were chiefly conducted in relation to the transformations of the bed morphology, i.e. near the bed.

Sediments moving close to the bed are almost fine sands, containing a very small percentage of clay, and sediment transport rates are very low. For these reasons, continuous samplers were prefered to instantaneous ones.

Twortypes of instruments were used : the Delft bottle (D.F.) and the Bed load Transport Meter Arnhem (B.T.M.A.), both developped in the Netherlands. The Delft bottle was used in two versions. For measurements close to the bed, it was mounted on a sleigh, and the inlet, having a diameter of $0.015 \mathrm{~m}$ or $0.022 \mathrm{~m}$ depending on the velocity, may be positioned at $0.05 \mathrm{~m}, 0.15 \mathrm{~m}, 0.25 \mathrm{~m}$ or $0.35 \mathrm{~m}$ from the bed. For the rest of the water column, i.e. $0.40 \mathrm{~m}$ from the bottom to the water surface, an integrated sample is taken with a suspended Delft bottle, at 4 to 8 levels depending on the total depth. At each level, the sampling time was fixed to 5 minutes. At each station four time - integrated samples were taken with the Delft bottle mounted on a sleigh (D.F.2), and one time - and depth - integrated sample with the suspended Delft bottle (D.F.1). Sample volume varies from a fraction of a cubic centimeter to a few hundreds cubic centimeters.

The B.T.M.A. sampler, sometimes called the Dutch sampler, is composed of a rigid rectangular entrance, $0.085 \mathrm{~m}$ wide and $0.05 \mathrm{~m} \mathrm{high}$, connected by a diverging rubber neck to a basket of $0.2 \mathrm{~mm}$ mesh. The B.T.M.A. samples a layer of a thickness of $0.05 \mathrm{~m}$ on the bottom, usually during 2 minutes.

Only the sand fraction of the sediments is withhold in these instruments. The sizes of the samples are determined with the visual accumulation tube.

The Delft bottle on a sleigh and the B.T.M.A. are lowered on the 
bottom very carefully without disturbing the bed. However, it is not possible to know if the entrance of the B.T.M.A. do not scoop the bottom sediment. Therefore, four samples are taken at each station.

Special attention was paid to the location of D.F.2 and B.T.M.A. on the bedforms using echosoundings. Indeed, measurements in the dead zone of the brough of a dune are meaningless.

At each station, the velocity profile was measured and the bottom shear velocity computed.

RESULTS

Three types of results will be discussed : variation in bed load and suspended load discharges at constant mean velocity; distribution of transport rates near the bottom; distribution of sediment transport in a cross-section.

Variation of sediment transport at constant mean velocity (Fig.7). During periods of high river discharges, the influence of tides on the mean current is negligible at the head of the braided area. During the flood of 1973, variations of sediment transport were measured during a 7 hours period. The tidal amplitude at the sampling station was $0.03 \mathrm{~m}$, and the mean velocity, $1.3 \mathrm{~m} / \mathrm{s}$, did not vary significantly. Two Delft bottles on a sleigh mounted with the inlet at $0.05 \mathrm{~m}$ from the bottom, were used simultaneously in order to increase the number of observations. The distance between these instruments was about $50 \mathrm{~m}$ in a $3000 \mathrm{~m}$ wide channel with depths of about $9 \mathrm{~m}$. Hourly averages of the sediment transport were estimated for the two Delft bottles D.F.2a and D.F.2b, and for the bed load sampler B.T.M.A.

Using Bagnold's approach $|1|$, bed load and suspended load were calculated. The method was modified in order to provide results in an isolated station, using the power of the flow as the product of the mean velocity and bottom shear stress deduced from the vertical velocity distribution. Sediment sizes used in the calculations were hourly weighted averaged values. Bed load measured with sampler B.T.M.A. evolves erratically. Mean values are higher during the 4 hours period preceding low water, than during the 3 hours period following low water. Sediment transport rates at $0.05 \mathrm{~m}$ from the bottom measured with samplers D.F.2 are less irregular, 


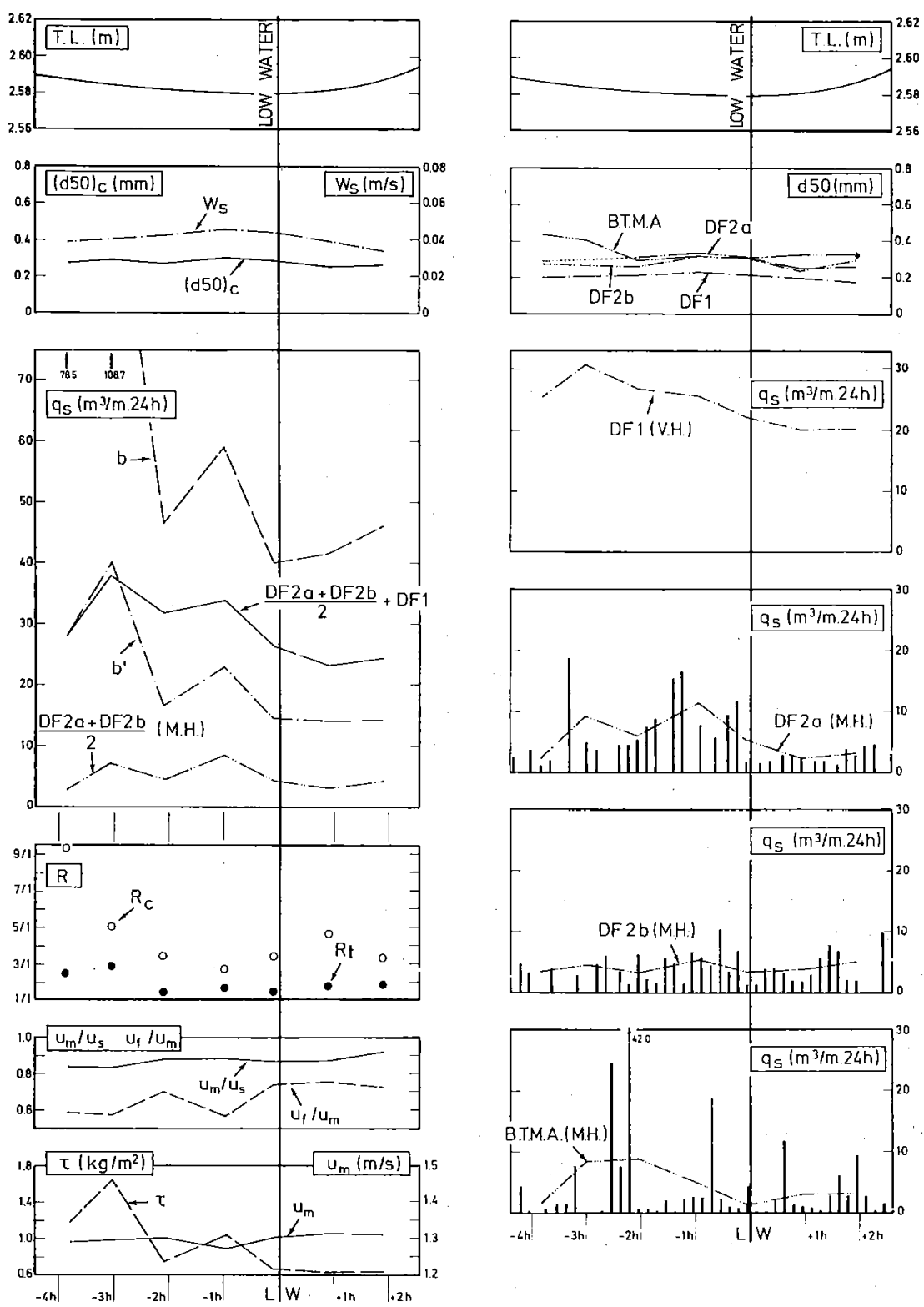

Fig.7. Variation of sediment transport at constant mean velocity under the influence of a very small tide. 
but mean values have the same order of magnitude as bed load data. Suspended load measured with sampler D.F.J varies regularly, higher values being observed before low water.

Measured sediment transport rates and computed sediment transport capacities of bed load $b^{\prime}$ evolve similarly. The ratios between these transport capacities computed with the modified Bagnold's approach and sediment transport rates measured with the samplers, are just given here as an indication, these data having not the same meaning.

The influence of bottom shear stress seems to be clearly demonstrated. Unfortunately, direct measurements of Reynold stress and turbulent kinetic energy could not be achieved in the boundary layex. Nevertheless the observed variations could be related to a burst - sweep cycle, and further research will be oriented in this direction.

Distribution of transport rates near the bed (Fig.8).

Generally, sediment transport is intense in a layer of a thickness of a few centimeters to a few decimeters, moving close to the bed. It is difficult to make a distinction between bed load and suspended load, but probably most of the solid particles in this layer moving by saltation rather than suspended, contribute to the displacement of the bedforms, the large variations of bed load sampled with the B.T.M.A. sampler, and the less erratic transport measured with the D.F.2 sampler in this layer strongly suggests a possible contribution of the burst - sweep cycle to these phenomena.

Distribution of sediment transport in a cross-section.

Several water and sediment discharge measurements were performed in various channels in order to relate their spatial distribution and their variability during floods. The sediment input of the main channel of the braided area is controlled in the cross-section of Ntua-Nkulu, where the river discharge represents $86 \%$ of the total fresh water inflow of the estuary. An example of field data and calculations is given in figure 9. The plume of suspended particles observed near the left bank is due to the presence of a rock, inducing intense secondary currents. The remarkable distribution of sediment sizes in the $1800 \mathrm{~m}$ wide cross-section is also due to morphological factors and an analysis of sediment transport distribution should take these factors into account. The agreement between sediment transport rates measured with samplers D.F.2 and D.F.1, 


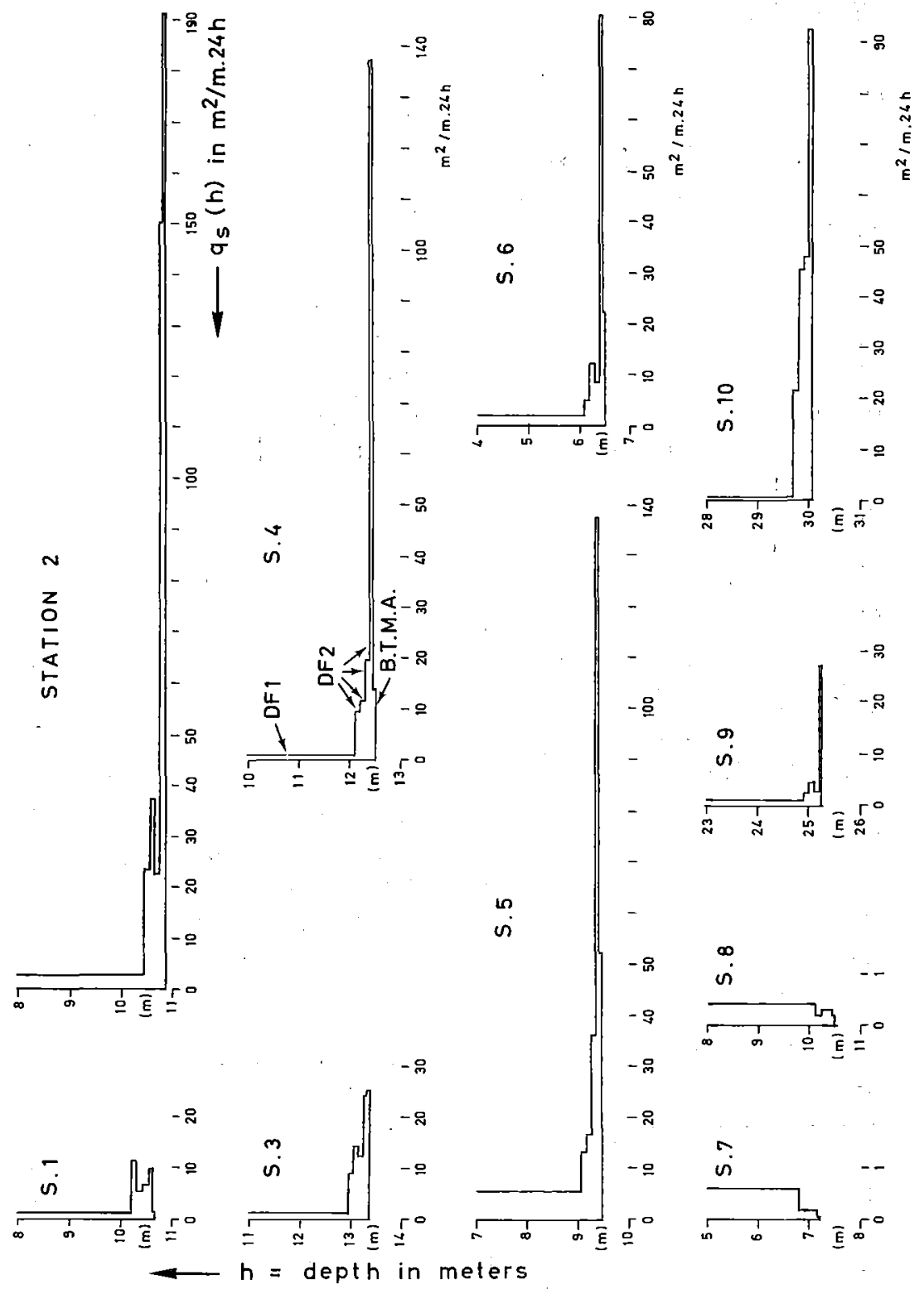

Fig.8. Distribution of sediment transport rates near the bed. Cross - section of Ziamanganga. September 1969. 

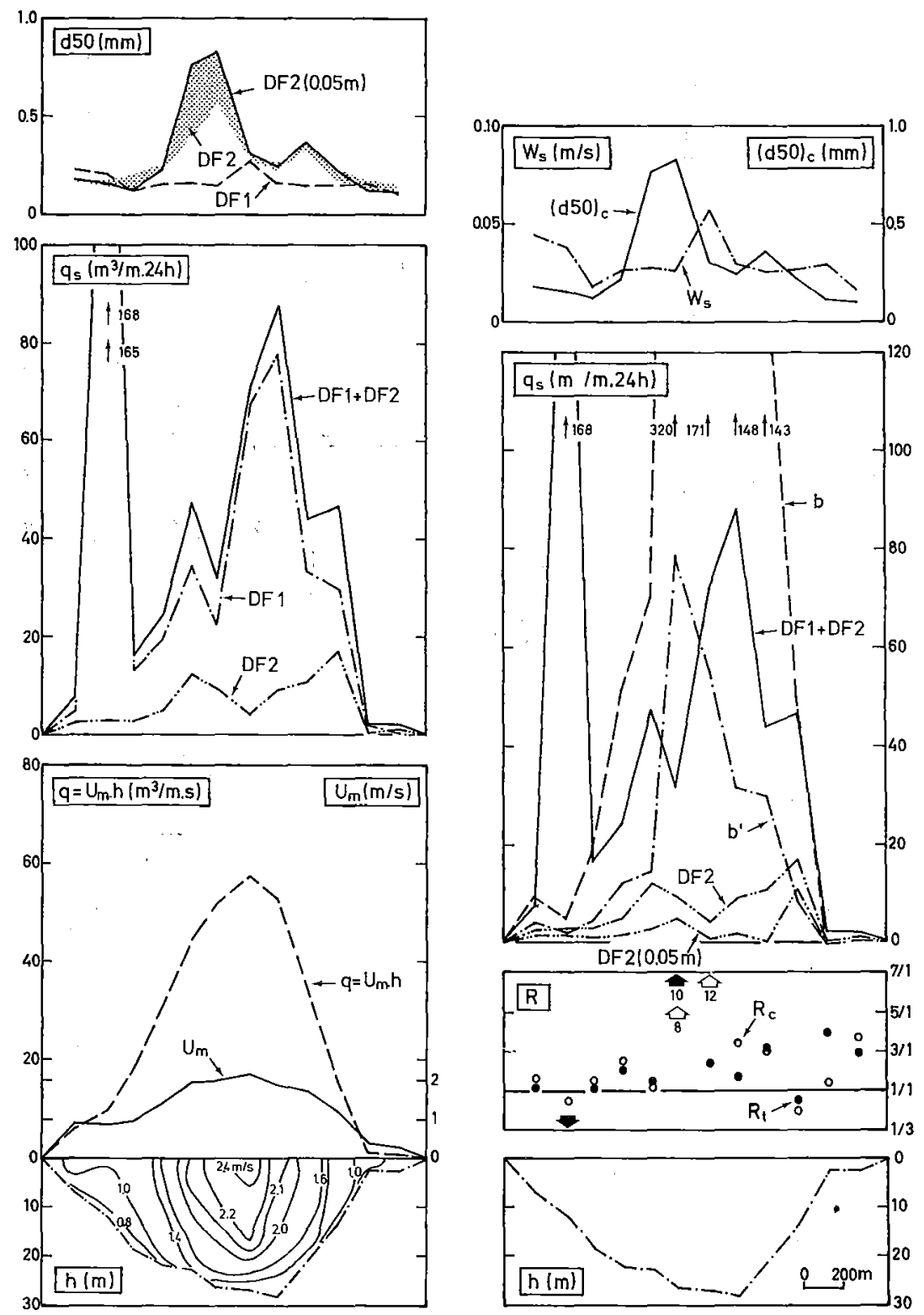

Fig.9. Distribution of sediment transport in the control section of Ntua-Nkulu. Gauging of November 1973. 
and calculated sediment transport capacities is satisfactory, with exception for stations 11,7 and 6 , for the reasons mentioned above. Using Bagnold's approach with mean characteristics of flow and sediments, calculated total transport capacity amounts to $245000 \mathrm{~m}^{3}$ per day instead of $145000 \mathrm{~m}^{3}$ per day using data of each station, while sediment transport measured with D.F. samplers amounts to $82000 \mathrm{~m}^{3}$ per day.

\section{CONCLUSIONS}

Sediment distribution and - transport in the Zaire estuary seem to be controlled by morphological factors. Measurements performed with Dutch samplers B.T.M.A, and Delft bottles, provide useful informations about the spatial and temporal distribution of transport. The bursting phenomenon is able to explain the very erratic transport observed on and near the bed, the existence of a layer close to the bed where sediment transport is intense, the difficulty to make distinction between bed load, suspended load, and sediment participating to the bed transformations. In further i.vestigations, an attempt will be made to relate sediment transport to the Reynold stress and turbulent kinetic energy.

In large alluvial streams, computations of sediment transport rates with mean flow and sediment data are not satisfactory. Even if Bagnold's approach is somewhere subject to criticism, the application of his formu1a to the Zaire estuary is almost successful, and tends to confirm the validity of power-related theories.

\section{REFERENCES}

11 R.A. Bagnold, 1966. An Approach to the Sediment Transport Problem from general Physics. United States Geological Survey Professional Paper 422-1, Washington, 37 pp.

\section{ACKNOWLEDGEMENTS}

The author wishes to acknowledge Mr.A.sterling, Director of the Be1gian Hydraulic State Laboratory for his continuous stimulation during this work. He is also indebted to Dr.R.Wollast for helpful discussions. This work is supported by the Belgian Foreign Ministry.

Field measurements were performed with the help of the Régie des Voies Maritimes of the République du Zaire. 
SYMBOLS USED IN. FIGURES 7 AND 9

b Transport rate of solids (total load) calculated with modified Bagnold's approach.

$b^{\prime} \quad$ Transport rate of solids (bed load) calculated with modified Bagnold's approach.

$b^{\prime \prime}$. Transport rate of solids (suspended load) calculated with modified Bagnold's approach.

B.T.M.A. Sediment transport rate measured

D.F.2 with samplers B.T.M.A., D.F.2 and D.F.1.

D.F.I

$\mathrm{d}_{50} \quad$ Size of sediments sampled with B.T.M.A., D.F.2 or D.F.1. $\left(\mathrm{d}_{50}\right)_{\mathrm{c}}$ Size of bed load used in calculations
with modified Bagnold's approach.

h Water depths.

M.H. Hourly average data.

q Water discharge per unit width $=u_{m}, h$.

$q_{s} \quad$ Solid discharge per unit width.

$R_{t}, R_{c} \quad$ Ratio between sediment transport rate of solids calculated with Bagnold's approach and sediment transport rate measured with Dutch samplers.

$$
\mathrm{R}_{t}=\frac{\mathrm{b}}{\text { D.F.2 } 2 \text { D.F.1 }} \quad \mathrm{R}_{\mathrm{c}}=\frac{\mathrm{b}^{\prime}}{\text { D.F.2 }}
$$

T.L. Tidal level.

$u_{m}$ Mean velocity.

$\mathrm{u}_{\mathrm{f}} \quad$ Velocity measured at $0.4 \mathrm{~m}$ from the bottom.

$\mathrm{u}_{\mathrm{s}} \quad$ Velocity measured at $0.3 \mathrm{~m}$ from the water surface.

V.H. Hourly data.

$\tau$ Bottom shear stress.

$\tau=\rho u_{t}^{2}$. 